\title{
Research on Dynamic Cost Control of Construction Project Based on BIM
}

\author{
Yaxi Wang \\ School of Economics and Management, Leshan Normal University, Leshan, Sichuan 614000, China \\ Email: youde77@163.com
}

\begin{abstract}
Keywords: BIM technology; Building construction; Cost control
Abstract. This paper expounds the necessity of dynamic cost control of construction projects. This paper introduces the connotation of BIM technology and the advantages of BIM software in project management potential. We also discuss the application of BIM technology in construction project, in order to control the cost of construction project, it provides useful reference for efficient development. This paper mainly discusses the cost and schedule control of project management in the BIM model.
\end{abstract}

\section{Introduction}

With the advent of the era of globalization, information is increasingly becoming the foundation of the global economy. Under the influence of modern information technology, modern construction project management has been transformed into the management of project information [1]. The traditional way of information communication can not meet the needs of modern large-scale construction projects, in practice many claims and disputes after all are caused by miscommunication or incomplete information $[2,3]$. How to create an integrated environment for the communication and coordination of construction project, improving the project construction efficiency has become a very important and urgent research topic in the field of domestic and international project management.

At present, in the research of information system theory, most of the domestic researches focus on the theoretical research of the whole system architecture [4]. The information of the construction industry in our country, at the best, is to provide some tools for the construction project management process, but not for the construction project management to bring about fundamental change. Foreign project management information system integration degree is higher, but it is only a few construction of information integration. In recent years, as a new development direction of building information technology, BIM has grown from an ideal concept to today's application tools, which brings many opportunities and challenges to the construction industry.

Profit maximization is the core work and the mostUltimate goal. In recent years, with the government's macro-control policies, the real estate market is increasingly standardized. In this context, more construction enterprises pay attention to the cost control work, and take it as the managementMiddle weight [5]. It is worth mentioning that the development of large projects, especially the large amount of data, increases the cost of the projectManagement difficulty. Precisely because of the existence of the above problems, the cost of development projects is difficult to control, resulting in unnecessary waste. Thus it can be seen that it is necessary to do well the cost control of construction projects which has become a top priority.

\section{The concept of BIM}

BIM is based on the most advanced 3D digital design solutions to the "visual" digital architectural models, for designers, architects and engineers. For designers, architects and engineers, the application of BIM requires not only the design tools to achieve the shift from 2D to 3D, but also need implement collaborative design, green design and sustainable design concept. The ultimate goal is to make the whole project in the design, construction and use of various stages, which can effectively achieve energy saving, cost savings, reduce pollution and improve efficiency. 
Building information model. The so-called building information model (BIM), refers to the real information, through the simulation of digital information building. The connotation of information is not only the geometrical description of visual information, also contains lots of non geometric information, such as the material of the fire resistance rating, component cost, purchasing information. In fact, BIM is through the digital technology, in the computer to build a virtual building, a building information model is to provide a single, complete and consistentbuilding information database.

Building information model refers to the physical and functional characteristics of facilities in the open industry standard, which can be calculated and related project life cycle. The integration of a variety of construction projects related information engineering data model. As a new computer software technology, BIM expanded from CAD to more software applications, such as project cost, schedule, but also has the potential to serve in equipment management. BIM add more intelligent tools to achieve more functional processes. In practical applications, BIM's information technology can help all project participants improve the efficiency and correctness of decision making. For example, the architectural design can be considered from 3D to hammer inside and outside the construction scheme, preparation of cement and other materials and material, property units can be used for visualization of property management. The project of BIM system in network environment based on real-time information, maintain and refresh, can provide access, increase, delete, change, make the relevant user architects, engineers and end-users. In the process of architectural design, construction and management, it speeds up the decision-making process, improves the quality of decision-making and reduces the cost of the project.

BIM construction project management information system analysis. The traditional construction project management information system can only stay in the department or single project interface, which is difficult to carry out mutual transmission timely and overall project[6]. The project management information system based on BIM can not only meet the requirements of the traditional management information system, but also meet the following requirements.

(1) Integrated management requirements. With the continuous promotion, more and more emphasis is placed on the integrated management of the project. Such asthe objective design, planning, control, cost management, schedule management, quality management.

(2) Life cycle management requirements. The whole life management concept is called the construction and management of the project should be considered in the whole life of the project on the platform in the construction project life cycle, by making the overall objectives of the project to achieve the optimal. Reflected in the construction of management information system, the construction of management information system is not only for the project implementation process, but also should be considered in the management information system into the application of enterprise operation stage in after the completion of the project, which can meet the needs of the owners of the actual work, and provides some summary data for the owners and construction supervision institutions...

BIM technology characteristics and applicability analysis. BIM is the abbreviation of Building Information Model, which is usually translated as building information model. In fact, BIM is a digital platform for the construction of the physical and functional characteristics of the project, which provide information for the target project sharing a resource platform for the project life cycle. Schematic diagram of BIM used in various fields is shown as figure 1. 


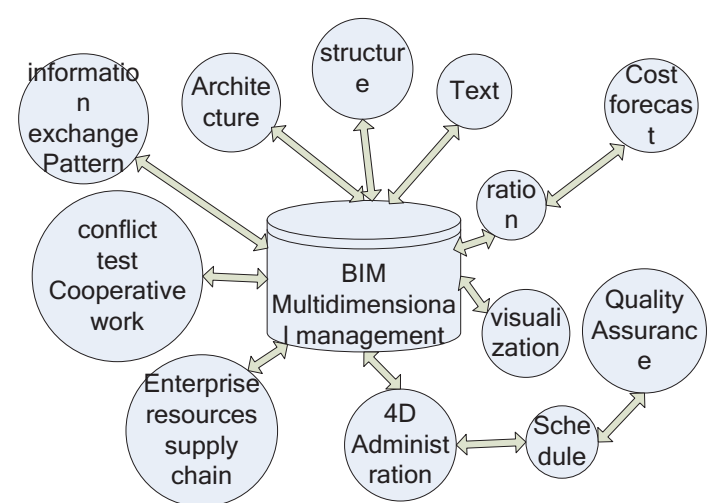

Figure 1 Schematic diagram of BIM used in various fields

\section{BIM engineering project}

Project management information system. The system uses B/S (Browser/Server) structure, through the Web browser, the user can access to WANwhich can achieve information sharing. Most of the transactions are realized by the server, and the data can be transmitted and processed by the connection between the terminal and the server.

The application of BIM in the application of cost management is mainly reflected in the rapid and accurate processing of engineering quantity information, which change the traditional thinking or the way of work, and significantly improve the calculation speed.

Improve the precision of engineering calculation. The introduction of BIM technology, which is based on the parameter model, has topological relations and 3D Boolean rules, the cost of personnel only according to local engineering calculation rules in BIM software to adjust the deduction calculation rules. the system will automatically complete the component reduction operation, more accurate and fast statistics of engineering quantity information. The cost of personnel from trivial quantities repeated calculations of liberation, in order to have the time and energy to engage in such as inquiry, group price more valuable work, which not only reduces the possible errors due to artificial calculation, and easy to fine management.

The progress of the project management of BIM technology through the construction process simulation based on repeated, let all the possible problems in the construction stage occurred earlier, in a simulated environment by modification, then used to guide the actual project construction, so as to ensure the smooth completion of construction projects.Figure 2 gives us the schedule management based on BIM technology.

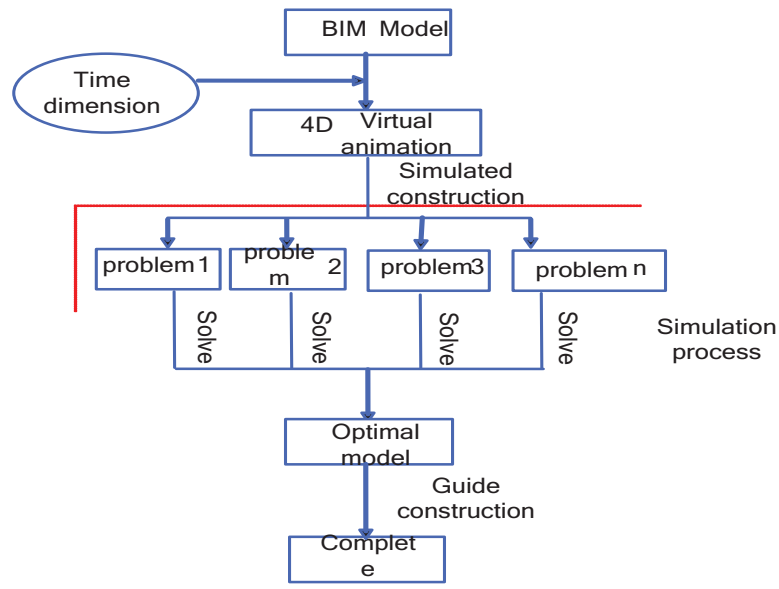

Figure 2 Schedule management based on BIM Technology

BIM technology in the construction of dynamic cost control applications. BIM technology can be applied to the engineering estimation from the decision-making stage to preliminary estimates, the design phase of the revised estimate and construction budget change the engineering measurement, construction process, visa payment schedule, arrange and plan funds deviation analysis 
finally, the whole process of project completion of the data collection and settlement management of the construction cost, Application of BIM in construction cost management is shown in figure 3.

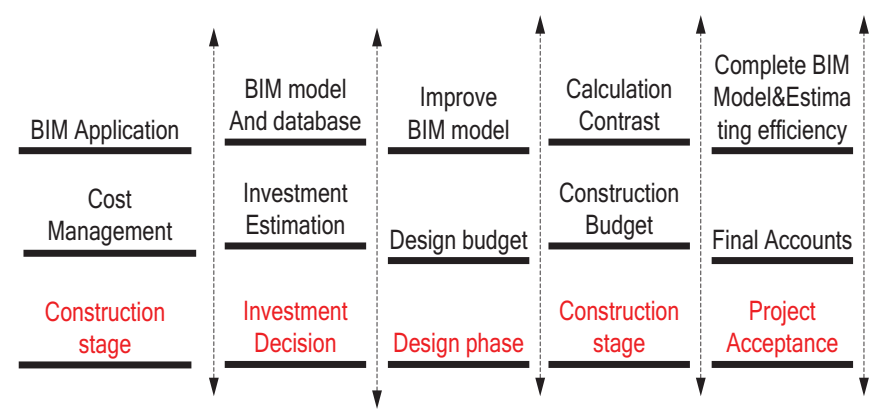

Figure 3 Application of BIM in construction cost management

Decision stage. The characteristics of the operation use the BIM parameter and the component, with the help of BIM model BIM model similar to previous projects or simply set up the project, you can quickly statistical engineering quantity information and complete the preparation work in project investment estimation which don't need drawings of the case.

The decision stage, compiled using BIM technology to quickly and accurately complete the project estimates, introducing BIM to provide data support for the correct decision, which has changed the traditional project evaluation work mode.The cost engineer on the basis of the experiencemakes project estimation play a guiding role in the late stage of cost control.

Design stage. The engineering design is the key link of the project cost control, which plays a decisive role in the construction period of the project, the project cost, the quality of the project and whether it can play a better economic benefit after the completion of the project.At the same time, the import BIM models of various professional collision checking software, such as Navisworks, which found that the pipe collision problem of different systems in advance, reduce or avoid caused by rework costs caused by waste and delay. The use of relational database BIM model, quickly and accurately obtain engineering basic data split physical quantity in the design process, which analysis method of implementation to provide timely and accurate data support for the quota design and value engineering.

With the strengthening of the design depth, BIM model contains the engineering information which is constantly updated and improved, such as decoration engineering details, details of the material practice. Automatic deduction function using BIM model component avoid the manual calculation caused by unnecessary errors, and save a lot of time, so that cost engineers can put more energy into more meaningful work, such as inquiry or quantity analysis... In the BIM model, the time dimension is introduced to construct the 4D-BIM model, which can be used for virtual construction, and provide technical support for the reasonable arrangement of construction schedule. Such as the construction of the simulation process, the virtual from the base to the main body to the final decoration of the entire construction process.

Construction stage. During the construction stage of construction project cost management, the main task is through the project payment control engineering change cost control, and mining the cost saving potential to control the actual cost which does not exceed the planned investment. Under the traditional mode, when the contractor in accordance with the time stipulated in the contract to the employer to submit finished work report, the project management institutions need to spend a lot of time and effort to verify the report submitted by the contractor, the project management institutions also need to check whether the amount of accurate, at the same time for on-site inspection of the finished project quality. When the contractor has finished the project report, it also needs to spend a lot of manpower and time to complete the project. The efficiency and accuracy are difficult to be guaranteed. After the application of BIM technology in engineering measurement, it has completely changed the above work.

Because BIM technology integrates the time information, will be the building components and the time dimension associated with the parametric BIM model, according to the conditions needed for screening engineering information, engineering quantity statistics computer can automatically 
complete the relevant parts of the report and summary form. According to the construction schedule and the scene changes, update the BIM model database, using the Internet or LAN technology to realize data sharing, so the cost engineers can in their own authorized port fast and accurate statistics for a period.

\section{Summary}

The subject of cost control is very big, the meaning is also great. Cost control is related to low-carbon, environmental protection, green building, natural ecology, social responsibility, welfare and other grand narrative. As we all know, some natural resources are non renewable, so cost control is not only in the financial sense to maximize profits, the ultimate goal is to minimize the consumption of natural resources per unit building area.

BIM is an innovation in the history of construction information. The establishment of BIM based project management information system can express all the information of the project, which can be truly realized. The system can realize the integration of basic information management, project schedule management, quality management, financial management, project management and so on.Information support system can provide multidimensional industry planning and decision-making. With the development of BIM, it is not only the progress of the existing technology, but also the transformation of production organization mode and management mode.

\section{References}

[1] Wen Y. Research on Cost Control of Construction Project Based on the Theory of Lean Construction and BIM: Case Study[J]. Open Construction and Building Technology Journal, 2014, 8: 382-388.

[2] Grover R, Froese T M. Knowledge Management in Construction Using a SocioBIM Platform: A Case Study of AYO Smart Home Project[J]. Procedia Engineering, 2016, 145: 1283-1290.

[3] Mancini M, Wang X, Skitmore M, et al. Editorial for IJPM special issue on advances in building information modeling (BIM) for construction projects[J]. 2017.

[4] Sun K, Shang Z, Li S, et al. Exploration of Sustainable Design of Architectural Engineering and Construction Project base on BIM[J]. 2015.

[5] Zhang, S., Sulankivi, K., Kiviniemi, M., Romo, I., Eastman, C. M., \& Teizer, J. (2015). BIM-based fall hazard identification and prevention in construction safety planning. Safety science, 72, 31-45.

[6] Merschbrock C, Munkvold B E. Succeeding with building information modeling: a case study of BIM diffusion in a healthcare construction project[C]//System Sciences (HICSS), 2014 47th Hawaii International Conference on. IEEE, 2014: 3959-3968. 